\title{
Degradation of Gaseous Formaldehyde by Visible Light-Responsive Titania Photocatalyst Filter
}

\author{
Tun-Ping Teng, ${ }^{1}$ Tun-Chien Teng, ${ }^{2}$ and Shu-I Pan ${ }^{1}$ \\ ${ }^{1}$ Department of Industrial Education, National Taiwan Normal University, No. 162, Section 1, He-Ping E. Road, \\ Da-an District, Taipei City 10610, Taiwan \\ ${ }^{2}$ Department of Mechatronic Technology, National Taiwan Normal University, No. 162, Section 1, He-Ping E. Road, \\ Da-an District, Taipei City 10610, Taiwan \\ Correspondence should be addressed to Tun-Chien Teng, walter.teng@ntnu.edu.tw
}

Received 2 September 2011; Revised 13 November 2011; Accepted 13 November 2011

Academic Editor: Jiaguo Yu

Copyright (๑) 2012 Tun-Ping Teng et al. This is an open access article distributed under the Creative Commons Attribution License, which permits unrestricted use, distribution, and reproduction in any medium, provided the original work is properly cited.

A method is proposed that uses electrophoretic deposition (EPD) to fabricate the titania $\left(\mathrm{TiO}_{2}\right)$ photocatalyst filter and then successfully modifies it by lithium nitrate $\left(\mathrm{LiNO}_{3}\right)$ to be visible light responsive such that the modified photocatalyst filter effectively degrades gaseous formaldehyde. The performance of degrading gaseous formaldehyde is evaluated in the photocatalytic circulation reactor for different temperature and light sources. The results show that the modified $\mathrm{TiO}_{2}$ photocatalyst filter has much better degradation performance for gaseous formaldehyde than the original $\mathrm{TiO}_{2}$ photocatalyst filter regardless of light source, and the performance is better at the higher ambient temperature. The best total average degradation performance of the modified photocatalyst filter is about $9.2 \%$ and $16.3 \%$ higher than the original photocatalyst filter (P-25, Degussa) for the UVA and visible irradiation, respectively, at $26^{\circ} \mathrm{C}$.

\section{Introduction}

With the growth of the global economy, the kinds of the material used in interior decorating are gradually diversified. The woods and paints widely used in interior decorating usually contain organic solvent such as formaldehyde, and the solvent gradually volatilizes into the air to degrade the quality of the indoor air. When people require higher quality of the indoor air, how to eliminate the volatile organic gaseous pollution becomes an important research topic in the recent year. With the development of nanotechnology, utilizing degradation reaction by photocatalyst to eliminate the organic pollution is a hot topic [1-3]. The research topic on eliminating the organic pollution by the photocatalyst includes how to coat the photocatalyst material and how to excite photocatalytic reaction by visible lights. To coat the photocatalyst material firmly on the substrate is the first step to apply the photocatalyst material in HVAC (heating, ventilation, and air conditioning) system and air cleaning $[4,5]$. The coated material must not peel off to result in the second pollution for the long time use and even can be reusable after wash. Further, if the material can be modified to be responsive to visible light (visible light responsive) instead of being only responsive to ultraviolet light (UV light responsive), the material can be used as photocatalyst indoors with no need of the extra UV or even artificial light source and thus can be more widely and practically used.

Photocatalytic film can be fabricated in many ways, but the most popular methods are sputtering [6], chemical vapor deposition (CVD) [7], sol-gel [8], spin coating [9], and electrophoretic deposition (EPD). The EPD method is low cost and can easily form thin films with different materials on irregular-shaped objects just by a simple setup [10-14]. Many researchers use organic solvent suspensions, such as acetylacetone and isopropanol as the working fluids in the EPD process [15-18]. Using organic solvents can prevent bubble formation during water electrolysis and suppress the Joule heating effect and electrochemical attacks on the electrode [19]. Due to the recent awareness of environment protection, some other studies report that aqueous suspensions are used as electrophoretic working fluids. In recent years, several researchers have already proposed some 
practical techniques to solve the above problems of water electrolysis. These studies also report the successful fabrication of $\mathrm{TiO}_{2}$ nanophotocatalytic films $[20,21]$ and other materials coating $[22,23]$. Although aqueous suspensions in EPD process have some disadvantages including cracks, unevenness, and holes in the deposited film, the EPD has advantages of low cost and relatively less pollution. The poor quality of the film caused by bubbling during the EPD process can be improved by adding surfactants or dispersants $[24,25]$.

As the main excitation light source for $\mathrm{TiO}_{2}$ photocatalyst is UV light, and the UV and visible light share $4 \%$ and $43 \%$, respectively, in the solar spectrum, it results in decline in the pracitcality of $\mathrm{TiO}_{2}$ photocatalyst [26]. Therefore, it is an important research direction to modify the $\mathrm{TiO}_{2}$ photocatalyst to be excited under the visible light irradiation. The main two ways to modify $\mathrm{TiO}_{2}$ photocatalyst to be visible light responsive are as follows: first, add metal ion to modify the $\mathrm{TiO}_{2}$ photocatalyst, which can effectively degrade the phenol, 2,4-dinitroaniline, Malachite green oxalate, 4hydroxybenzoic acid, benzamide, rhodamine $\mathrm{B}(\mathrm{RhB})$, and formaldehyde under the visible light irradiation [26-30]. Second, add nonmetallic materials to modify $\mathrm{TiO}_{2}$ photocatalyst, which can effectively degrade the nitrogen monoxide (NO), acetone, and formaldehyde and be used for water treatment under visible light [30-35]. Except for the kinds of the adding material, concentration, shape, and structure of $\mathrm{TiO}_{2}$ also have effects on the degradation of pollutants [27$29,36]$. Furthermore, the spectra of the exciting light source also affect photocatalytic degradation of pollutants [31].

The gaseous formaldehyde is the most common indoor pollutants. Regarding decomposition of the $\mathrm{TiO}_{2}$ photocatalyst for gaseous formaldehyde, the main kinds of the related research are described as follows: first, increase the specific surface area and porosity of $\mathrm{TiO}_{2}$ to promote the utilization of light irradiation and adsorption to enhance the effect of $\mathrm{TiO}_{2}$ on decomposing gaseous formaldehyde. The related methods include mixing $\mathrm{TiO}_{2}$ with the porous material, activated carbon [37] or zeolite [38], to enhance the effects on adsorbing and decomposing gaseous formaldehyde. Moreover, the chemical precipitation-peptization method was used to produce $\mathrm{TiO}_{2}$ hydrosols with an anatase crystal structure which had smaller particle sizes, higher surface areas, larger porosity, and higher transparence to enhance the effect on decomposing gaseous formaldehyde [39]. Second, produce $\mathrm{Pt} / \mathrm{TiO}_{2} / \mathrm{Al}_{2} \mathrm{O}_{3}$ photocatalyst on an anodic alumite plate by the electrodeposition technology to increase adsorption of oxygen which is activated and quickly formed into $\mathrm{O}: \mathrm{Pt}_{\text {surface }}$ species at ambient temperature for further photocatalytic decomposition of formaldehyde [40]. Third, dope other materials to lower the energy gap and make the $\mathrm{TiO}_{2}$ photocatalyst to be visible light responsive in order to increase utilization of the light spectrum and performance of decomposing gaseous formaldehyde. The doped materials include $\mathrm{Cr}$ ion to form $\mathrm{Cr} / \mathrm{TiO}_{2}$ [30]; N, and $\mathrm{S}$ to form $\mathrm{N}$, $\mathrm{S}$ codoped $\mathrm{TiO}_{2}$ [32]; C, $\mathrm{N}$ and $\mathrm{S}$ to form $\mathrm{C}, \mathrm{N}, \mathrm{S}$ tridoped $\mathrm{TiO}_{2}$ powders [33]; $\mathrm{N}$ and $\mathrm{F}$ to form $\mathrm{N}-\mathrm{F}-\mathrm{TiO}_{2}$ [41]. All the above doped material can greatly aid decomposing gaseous formaldehyde.

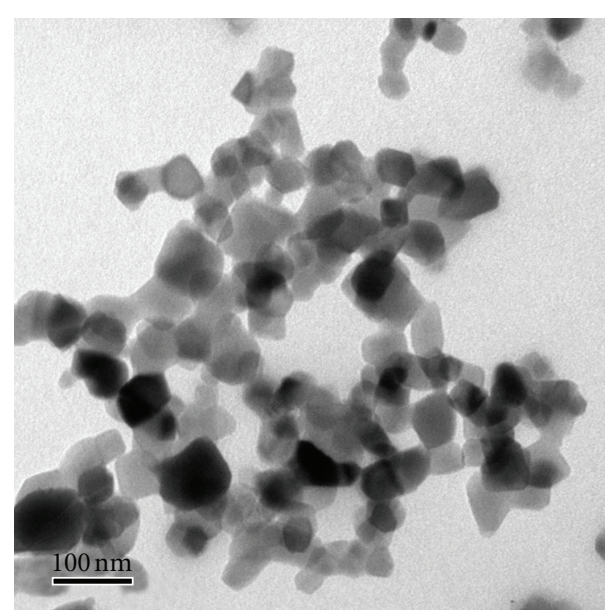

FIgUre 1: TEM images of $\mathrm{TiO}_{2}$ nanoparticles.

From the above literatures and discussion, one can find that the $\mathrm{TiO}_{2}$ photocatalyst has excellent degradation performance for many pollutants, and several techniques can modify $\mathrm{TiO}_{2}$ photocatalyst that is originally UV light responsive to be visible light responsive. In this study, the photocatalyst was coated on a stainless steel plate with holes to form the photocatalyst filter by EPD. The working fluid of EPD was $\mathrm{TiO}_{2} /$ water nanofluid prepared by two-step synthesis method. Alginate was added as an anionic dispersant to change the zeta potential of $\mathrm{TiO}_{2}$ particles, and thus the $\mathrm{TiO}_{2}$ nanoparticles that originally deposited on the cathode would change to deposit on the anode, which could effectively reduce the bubble problem in water electrolysis leading to a poor film deposition. The photocatalyst filter was modified by $\mathrm{LiNO}_{3}$ and evaluated for the performance of degrading gaseous formaldehyde in the photocatalytic circulation reactor under different temperature and light sources.

\section{Experimental}

2.1. Materials. The phase of the $\mathrm{TiO}_{2}$ nanoparticles (P-25, Degussa) consists of $70 \%$ anatase and $30 \%$ rutile. Figure 1 shows transmission electron microscope (TEM, H-7100, Hitachi) image of the particles with an average particle size of about $20 \sim 40 \mathrm{~nm}$. In order to confirm the material of the sample used in this study again, $\mathrm{X}$-ray diffraction (XRD, D8 Advance, Bruker) using CuK_ $(\lambda=0.15418 \mathrm{~nm})$ radiation at $295 \mathrm{~K}$ was used for this purpose. All peaks were measured by XRD and assigned in comparison with those of the joint committee on powder diffraction standards data (PCPDFWIN 2.4) [42]. Figure 2 confirms that the major material used in this study was anatase $\mathrm{TiO}_{2}$.

2.2. Preparation of Working Fluid for EPD. The $\mathrm{TiO}_{2} /$ water nanofluid was fabricated by the two-step synthesis method in this study. First of all, we prepared a bulk liquid by adding $0.2,0.4$, and 0.6 wt. $\%$ of anionic dispersant (alginate, Alfa Aesar) to distilled water. This anionic dispersant reinforced the dispersion of $\mathrm{TiO}_{2}$ nanoparticles and changed the 


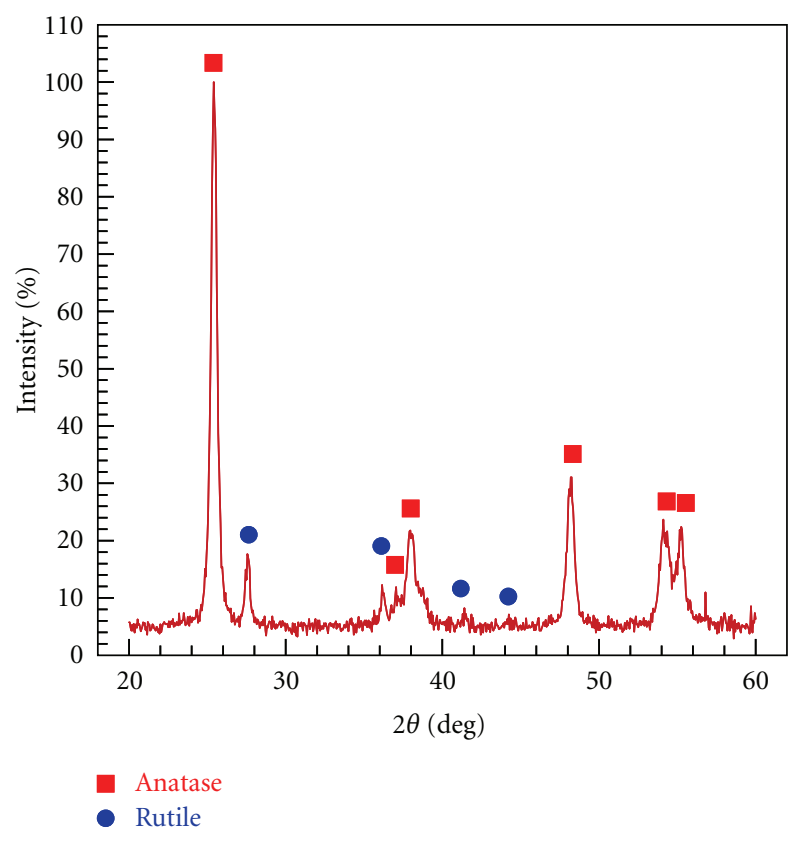

FIGURE 2: XRD patterns of $\mathrm{TiO}_{2}$ nanoparticles.

deposition direction of $\mathrm{TiO}_{2}$ nanoparticles [25]. The $\mathrm{TiO}_{2}$ nanoparticles were then measured by a precise electronic balance (XT-620 M, Precisa) and were added to the bulk liquid by several times to form the $\mathrm{TiO}_{2} /$ water nanofluid with a concentration of $1.0 \mathrm{wt} . \%$. In this nanofluid synthesis process, an electromagnetic stirrer, homogenizer, and ultrasonic vibrator were used to reinforce the dispersion and suspension effects. After preparation, the nanofluid was kept still for 24 hours. If no obvious deposition was observed, the fluid was used as the EPD process working fluid. The surface charge of the $\mathrm{TiO}_{2}$ nanoparticles was measured by a zeta potential analyzer (SZ-100, Horiba) to examine the effect of the added anionic dispersant on depositing on the anode. As shown in Figure 3, the measured zeta potential of the $\mathrm{TiO}_{2}$ nanoparticles without the anionic dispersant was about $28 \mathrm{mV}$, while that with the anionic dispersant was about $-58 \sim 66 \mathrm{mV}$. These results indicate that the zeta potential of the $\mathrm{TiO}_{2}$ nanoparticles changes from positive to negative after adding the anionic dispersant to the $\mathrm{TiO}_{2}$ /water nanofluid, which effectively deposits the $\mathrm{TiO}_{2}$ nanoparticles on the anode.

2.3. EPD Process. Figure 4 shows the EPD setup adopted in this study. To fix the electrophoretic electrode distance $(20 \mathrm{~mm})$, a 304 stainless steel EPD electrode was vertically fixed on a polypropylene (PP) holder. The stand was then placed in a glass beaker to form an EPD setup. The size of the flat electrodes 304 stainless steel plates was all $60 \mathrm{~mm} \times$ $10 \mathrm{~mm} \times 0.3 \mathrm{~mm}$. The length of the electrode actually immersed in the working fluid was $45 \mathrm{~mm}$. The EPD process in this study adopted various constant current power supply (EV243, Consort) levels (3, 5, 7, and $9 \mathrm{~mA})$ and various process durations $\left(3,5\right.$, and $7 \mathrm{~min}$.) for $\mathrm{TiO}_{2} /$ water nanofluid for each concentration of alginate.

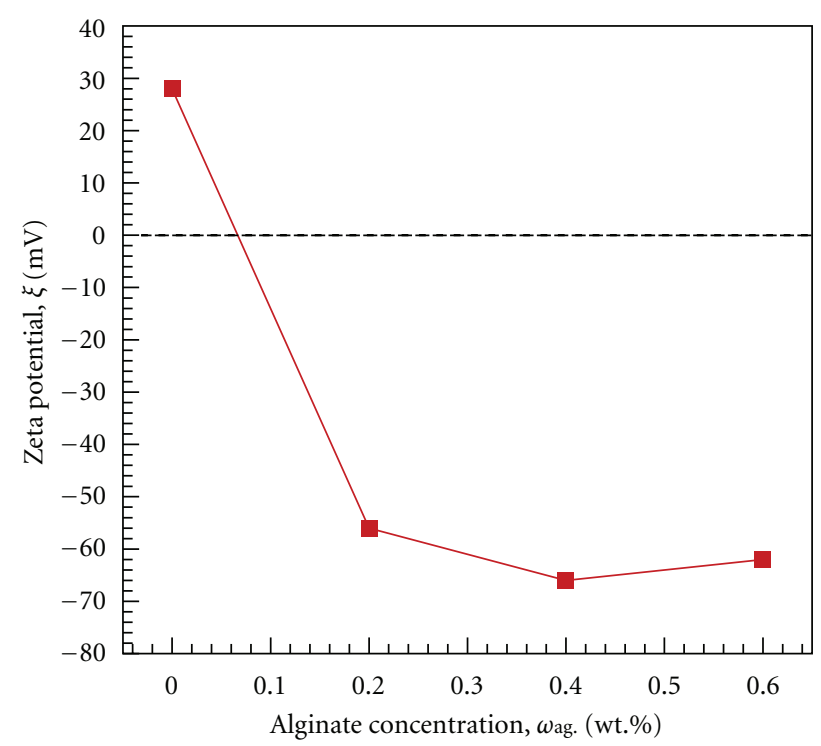

Figure 3: The zeta potential for the $1.0 \mathrm{wt} . \% \mathrm{TiO}_{2}$ nanoparticles suspended in base liquid.

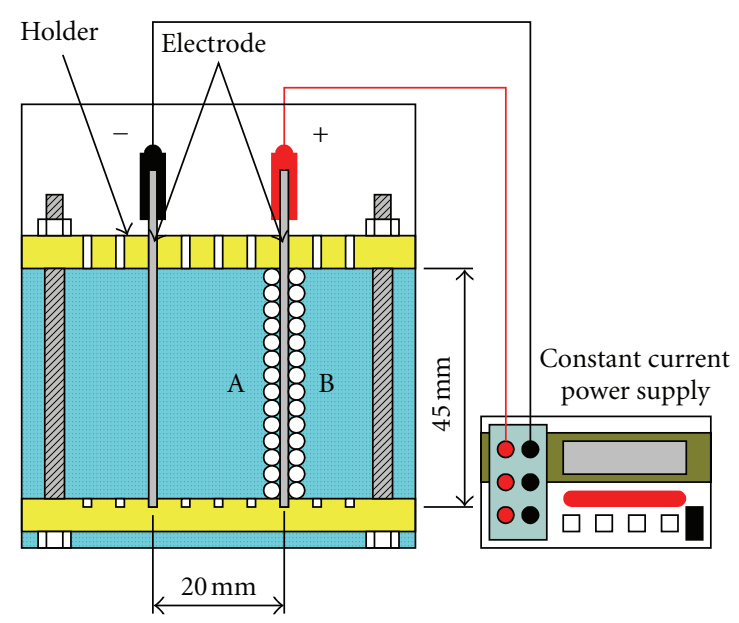

FIgURE 4: Experimental setup for EPD process.

2.4. Analysis and Modification of $\mathrm{TiO}_{2}$-Deposited Film. A film thickness meter (MiniTest 730, ElektroPhysik) with accuracy of $\pm 0.75 \%$ was used to measure the average thickness of the film made by EPD at 5 points of each sample for different experimental parameters on side A and side B of electrode plates. In order to keep the photocatalyst filter from peeling off to result in pollution in application, so we checked the samples and selected the process condition for producing the smoothest and cracks-free deposited film as the optimal EPD parameter by an optical microscope (BH2UMA, Olympus). Moreover, the surface of deposited film on the sample made at the optimal process parameter was checked again in higher magnification through a scanning electron microscope (SEM, JSM-6360, JEOL). The samples of the optimal photocatalyst deposition parameter were sintered by $300 \sim 700^{\circ} \mathrm{C} / 2 \mathrm{hr}$ in a high-temperature furnace, and then their crystalline state was, respectively, analyzed by 


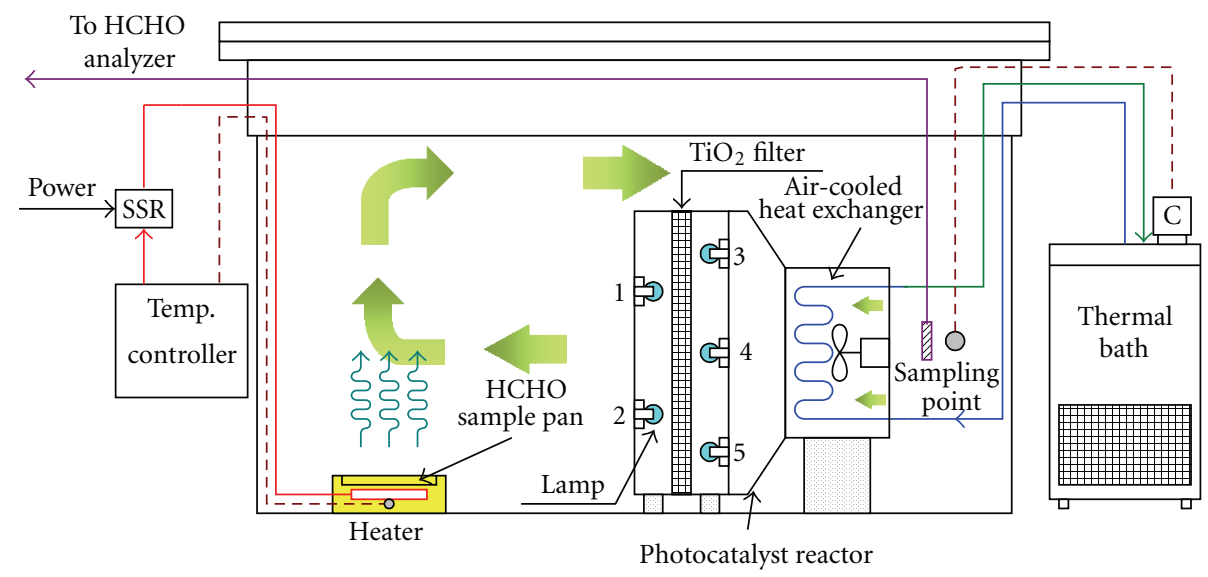

FIGURE 5: The installation of photocatalytic circulation reactor.

XRD in order to determine the optimal sintered temperature for manufacturing the photocatalyst filter. Next, the photocatalytic material was coated on a stainless steel plate (\#304, $80 \mathrm{~mm} \times 73 \mathrm{~mm} \times 0.3 \mathrm{~mm})$ with holes $(\phi=5 \mathrm{~mm})$ by EPD to produce the photocatalyst filter at the optimal photocatalyst deposition parameters. Further, the photocatalyst filter was immersed in $0.1 \mathrm{M}$ lithium nitrate $\left(\mathrm{LiNO}_{3}\right)$ aqueous solution for 20 seconds and through the drying process at $50^{\circ} \mathrm{C}$ in order to modify the original $\mathrm{TiO}_{2}$ photocatalyst filter to be visible light responsive $[28,29]$. Because the photocatalyst film deposited by EPD had porous structure, it easily adsorbed the dopant when it was immersed in $\mathrm{LiNO}_{3}$ aqueous solution. The main reason for using $\mathrm{LiNO}_{3}$ to modify the photocatalyst is that $\mathrm{Li}$ ion can reduce the energy gap of the $\mathrm{TiO}_{2}$ and thus make $\mathrm{TiO}_{2}$ responsive to the lights of longer wavelength. Further, $\mathrm{LiNO}_{3}$ is not a toxic chemical, so it is very suitable to be adopted in modifying photocatalyst for indoor air quality improvement.

2.5. Assess Degradation Performance for Gaseous Formaldehyde. The installation of photocatalytic circulation reactor is shown as Figure 5. The photocatalyst reactor consisted of the six photocatalyst filters (each dimension of photocatalyst filter was $80 \mathrm{~mm} \times 73 \mathrm{~mm} \times 0.3 \mathrm{~mm}$ ) on the holder and five lamps. Types of the five lamps were T5/8W of UVA lamps (F8T5/BL, GOODLY) or fluorescent lamps (TL8W/840, Philips) for different condition. Among the five lamps, three lamps were put toward the A-side of photocatalyst filter and the other two lamps toward the B-side. The gaseous formaldehyde was obtained by heating $0.5 \mu \mathrm{L}$ of $35 \mathrm{wt} . \%$ formaldehyde aqueous solution to evaporate at $40^{\circ} \mathrm{C}$. In order to maintain steady circulation of the gaseous formaldehyde in the photocatalytic circulation reactor, the air-cooled heat exchanger with a fan was installed in front of the reactor to maintain a constant wind speed and ambient temperature. Ambient temperature was set, respectively, at 26 and $22^{\circ} \mathrm{C}$ according to ASHRAE standard summer and winter [43]. The concentration of gaseous formaldehyde was measured by gaseous formaldehyde analyzer (YES plus, Critical Environment Technologies) for every 20 minutes. The formaldehyde analyzer measured the gaseous formaldehyde in the range of 0 to $10 \mathrm{ppm}$ with an accuracy of $0.05 \mathrm{ppm}$. The measurement for formaldehyde gas started at 10 minutes after instillation of formaldehyde aqueous solution and turned on the light source at 40 minutes after the measurement started in order to ensure that the measurement for the concentration change of the fully evaporated formaldehyde is mainly due to photocatalytic degradation.

In order to accurately determine the actual performance of the photocatalyst filter for degrading gaseous formaldehyde, the background absorption test is necessary. As the equipments also adsorb gaseous formaldehyde, one must measure the trend of the concentration of the gaseous formaldehyde as the experimental background value for the different photocatalyst filters with the light source being turned off. The test of background value for the original photocatalyst (nonmodified) filter is named "background 1", and the test for the modified photocatalyst filter is named "background 2" for the different light sources. The actual performance of the photocatalyst filter for degrading gaseous formaldehyde is evaluated by comparing the experimental measured value to the corresponding background value. All experimental parameters of this study are summarized in Table 1.

2.6. Data Analysis. In this study, for easy comparison of the actual performance of the photocatalyst filter for degrading gaseous formaldehyde, the "total average degradation performance $\left(\eta_{d}\right)$ " is introduced. The background values are used as baseline $\left(D_{b, \text { avg }}\right)$, and all the experimental data obtained for the different experimental parameters are compared with the corresponding baseline values. Moreover, the concentration of gaseous formaldehyde $\left(D_{d, k}\right)$ in the reactor is measured for every 20 minutes after the light is turned on. The $\eta_{d}$ is defined as

$$
\eta_{d}=\left[1-\frac{\left[\sum_{k=1}^{n} D_{d, k}\right] / n}{\left[\sum_{k=1}^{n} D_{b, k}\right] / n}\right] \times 100 \%
$$


TABLE 1: List of the experimental parameters.

\begin{tabular}{|c|c|}
\hline \multicolumn{2}{|c|}{ Fabrication of $\mathrm{TiO}_{2}$-deposited film by EPD } \\
\hline Concentration of $\mathrm{TiO}_{2}$ (wt.\%) & 1.0 \\
\hline Concentration of alginate (wt.\%) & $0.2,0.4$ and 0.6 \\
\hline Working current (mA) & $3,5,7$ and 9 \\
\hline Sintered temperature $\left({ }^{\circ} \mathrm{C}\right)$ & $300,400,500,600$ and 700 \\
\hline Concentration of $\mathrm{LiNO}_{3}$ for modification (M) & 0.1 \\
\hline \multicolumn{2}{|c|}{$\begin{array}{l}\text { Photocatalytic degradation for gaseous formaldehyde } \\
\end{array}$} \\
\hline Light source/power (W) & UVA and visible light (fluorescent lamps) $\times 5 / 8$ \\
\hline Filter type & $\begin{array}{l}\text { Original } \mathrm{TiO}_{2} \text { filter }(\mathrm{P}-25) \times 6(\text { background } 1) \\
\text { Modified } \mathrm{TiO}_{2} \text { filter }\left(\mathrm{P}-25+\mathrm{LiNO}_{3}\right) \times 6 \\
(\text { background 2) }\end{array}$ \\
\hline Ambient temperature $\left({ }^{\circ} \mathrm{C}\right)$ & 22 and 26 \\
\hline Volume of test pollutant $(\mu \mathrm{L})$ & 0.5 (35\% formaldehyde aqueous solution) \\
\hline Heating temperature for test pollutant $\left({ }^{\circ} \mathrm{C}\right)$ & 40 \\
\hline
\end{tabular}

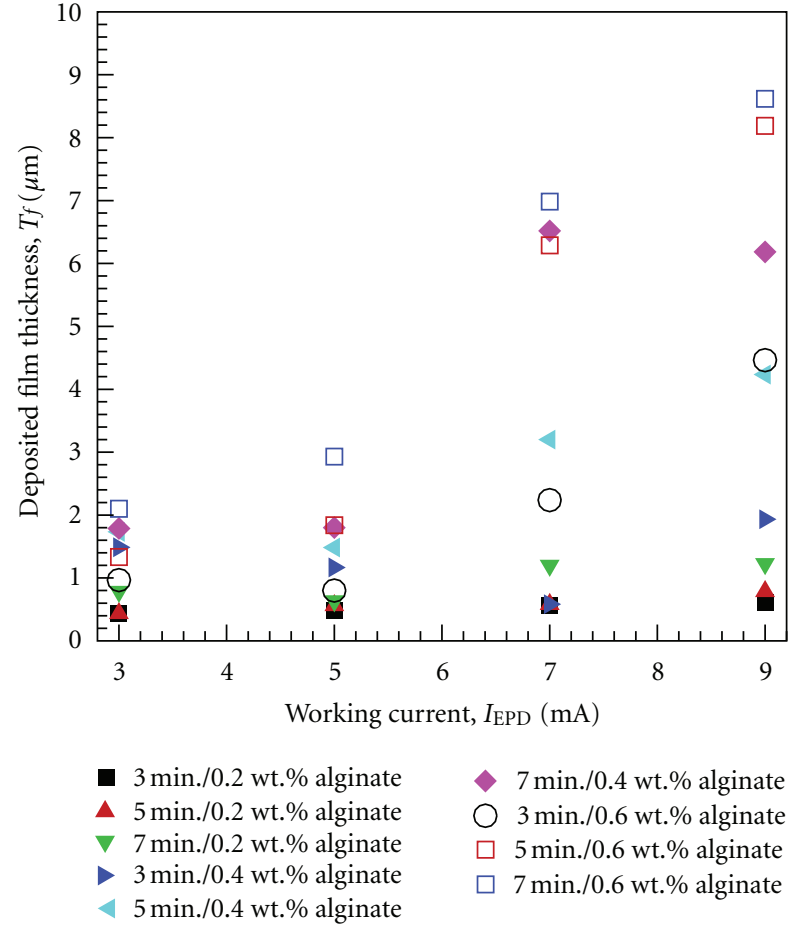

FIGURE 6: Deposited film thickness on side A varies with the working currents dispersant for different concentration and durations.

\section{Results and Discussion}

3.1. Characterization of the $\mathrm{TiO}_{2}$-Deposited Film Fabricated by EPD. Figures 6 and 7 show the variation of the thickness of deposited film on side $A$ and side $B$, respectively, for different working currents, dispersant concentration, and working durations. Both the figures show the film thickness generally trends up with increase in the working current, dispersant concentration, and working duration. However, in Figure 6, the deposited film thickness in some case is not proportional to the working current for the working

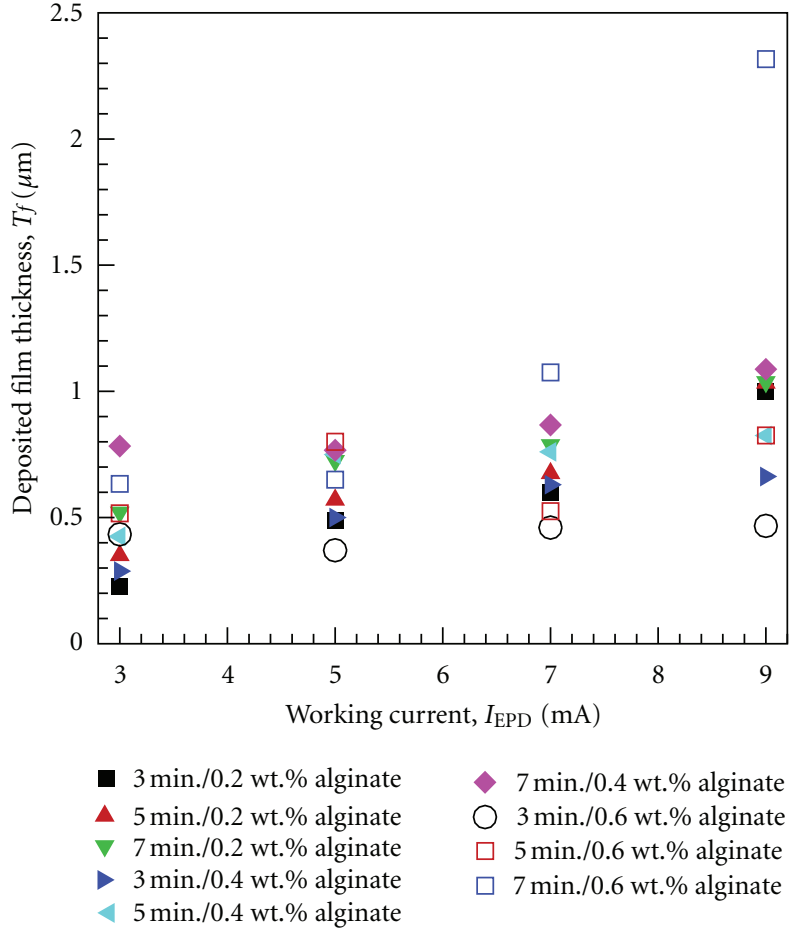

Figure 7: Deposited film thickness on side B varies with the working currents dispersant for different concentration and durations.

duration of 3 minutes. This phenomenon is mainly because the deposited film on the sample is prone to peel off due to its poor adhesion when the sample is removed from the working fluid if the deposition time is short. As the dispersant (alginate) increases the electric conductivity of the work fluid and thus increases the deposition rate, the film thickness is still roughly proportional to the working current even for the short working duration. Further, the longer working duration also increases the deposited film thickness and strengthens the deposited film. The above-mentioned problems can be resolved when the dispersant concentration 


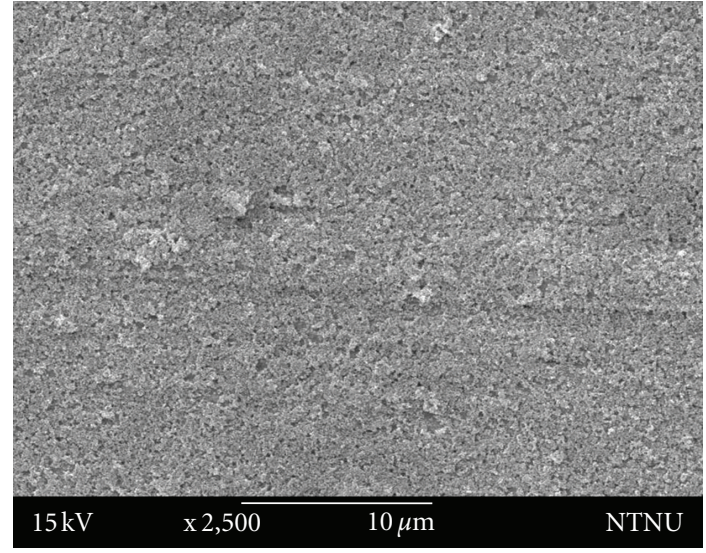

(a)

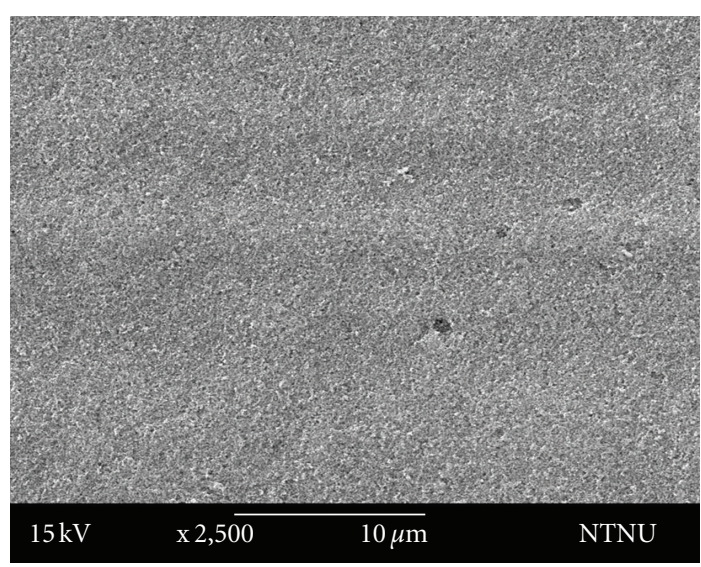

(b)

FIgUre 8: SEM photograph of the $\mathrm{TiO}_{2}$-deposited film at the optimal parameter of EPD, (a) side A, (b) side $\mathrm{B}$.

and working duration are raised up to $0.4 \mathrm{wt} . \%$ and five minutes, respectively. Furthermore, for the same experimental parameters, the thickness of the film on side $\mathrm{A}$ is greater than side B. As the working current increases, the difference becomes more obvious. This phenomenon is mainly because the electric field is stronger as the current increases and thus the nanoparticles in the suspension more easily deposit on side A through the shorter path. Therefore, thickness of the deposited film on side A is thicker than side B for the same parameters of EPD.

The optimal EPD parameters for manufacturing the photocatalyst filter are determined by checking the smoothness, uniformity, and crack of the deposited film through an optical microscope. The optimal process parameters of EPD in this study are as follows: $1.0 \mathrm{wt} . \% \mathrm{TiO}_{2}, 0.4 \mathrm{wt} . \%$ alginate, $9 \mathrm{~mA}$, and 5 minutes. With checking the samples through the optical microscope, one can find that the surface of deposited film is bumped and uneven when the deposition rate is too low, and the cracks appear when the deposition rate is too high. The SEM images of the deposited film made at the optimal EPD process parameters are shown in Figure 8. In Figure 8, one can find that either surface of side A or B is smooth and crack-free. Moreover, the surface roughness of side $\mathrm{B}$ is less than side $\mathrm{A}$ due to the lower deposition rate on side $\mathrm{B}$.

In order to increase the strength and adhesion of the deposited film, the samples made at the optimal parameters were sintered by $300^{\circ} \mathrm{C} \sim 700^{\circ} \mathrm{C}$ for 2 hours. Figure 9 shows the XRD patterns of the deposited film made at the optimal parameters for different sintered temperatures. In Figure 9, one can find that the crystalline state of rutile $(\mathrm{hkl}=110)$ has no significant growth when the sintered temperature is less than $600^{\circ} \mathrm{C}$, but has significantly grown when the sintered temperature reaches $700^{\circ} \mathrm{C}$. Regarding the surface condition, the cracks appear when the sintered temperature is above $500^{\circ} \mathrm{C}$. With considering the effect of photocatalyst and strength of the deposited film, the sintered temperature and duration for the deposited film of the photocatalyst in this study were set at $400^{\circ} \mathrm{C}$ for 2 hours.

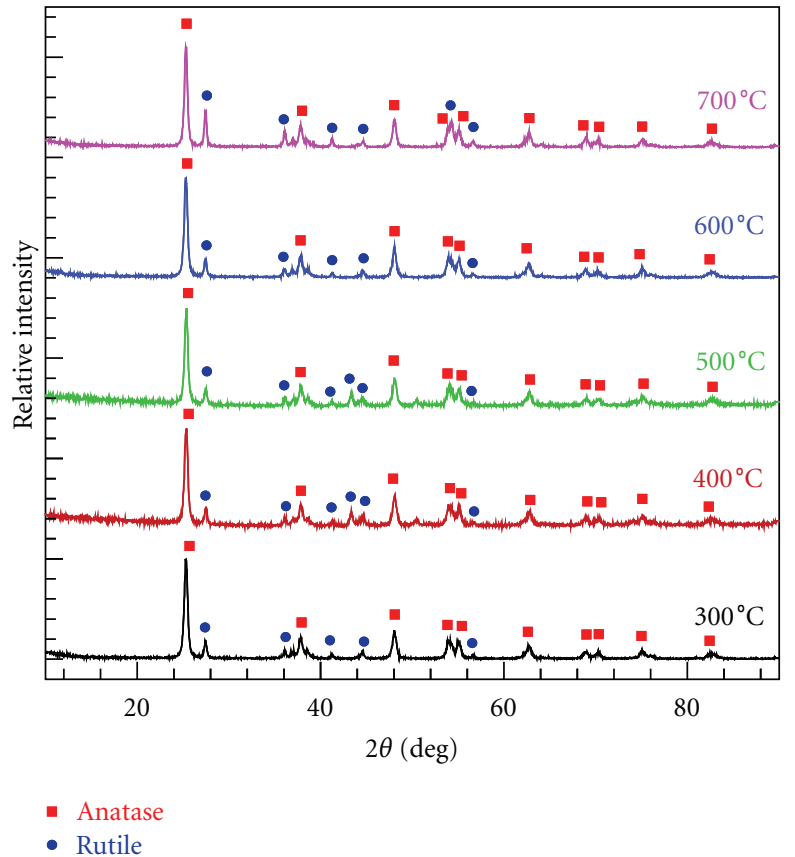

FIGURE 9: XRD patterns of the $\mathrm{TiO}_{2}$-deposited film sintered at different temperatures.

\subsection{Effect of Various Parameters on Photocatalytic Degradation for Gaseous Formaldehyde}

3.2.1. UVA Light Irradiation. Figures 10 and 11 illustrate the degradation for gaseous formaldehyde in the cases with different temperature and types of photocatalyst filter under UVA light irradiation. In those figures, one can find that the highest concentration of the gaseous formaldehyde appears at 100 to 120 minutes after the circulation reactor starts. It is mainly because the drops of formaldehyde aqueous solution have been completely vaporized at that moment to reach the peak concentration. In addition, the UVA lights are turned on at 40 minutes after the circulation reactor starts and thus 


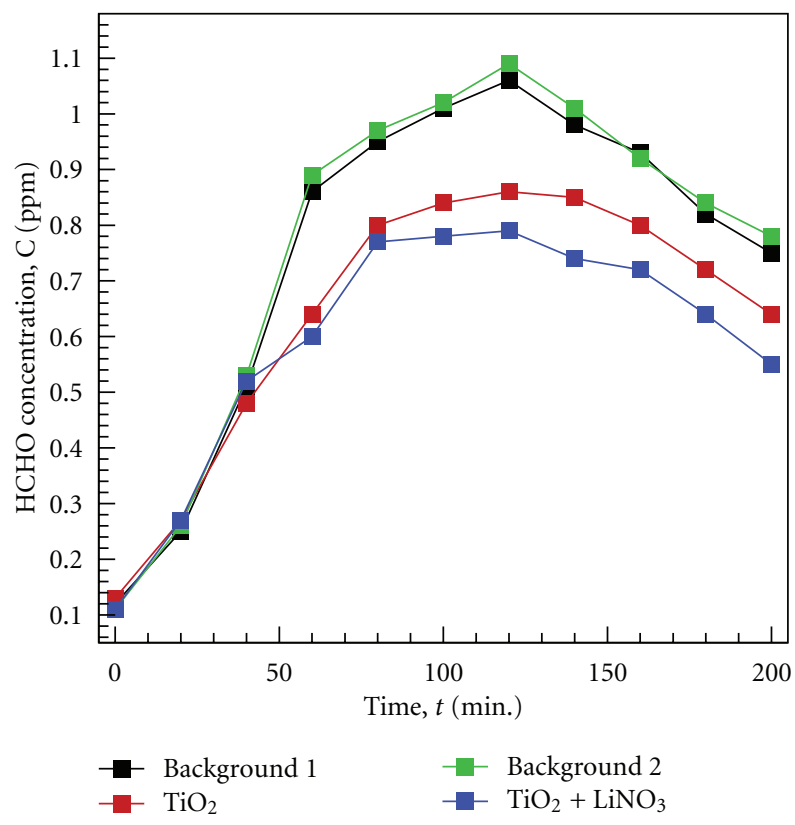

FIGURE 10: The degradation performance for gaseous formaldehyde under irradiation of UVA lamps at $26^{\circ} \mathrm{C}$.

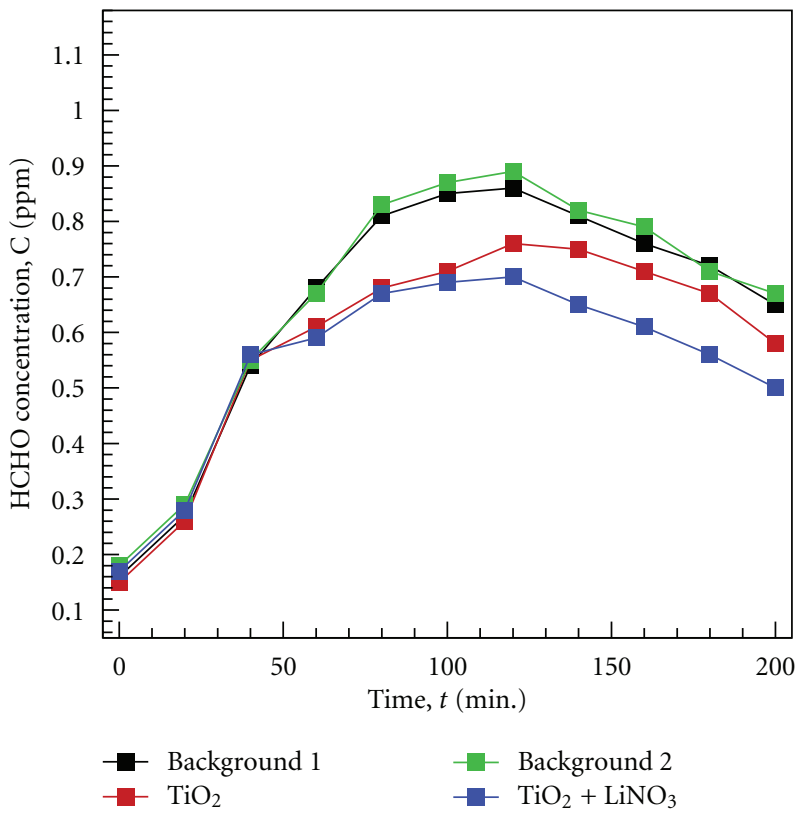

FIGURE 11: The degradation performance for gaseous formaldehyde under irradiation of UVA lamps at $22^{\circ} \mathrm{C}$.

the reduced concentration is compared with the background test. Therefore, the photocatalyst filter is proved to effectively degrade the gaseous formaldehyde through photocatalytic reaction. By the way, the concentration in the background test for the modified photocatalyst filter (background 2) is higher than that for the original photocatalyst filter (background 1). This phenomenon is mainly because the surface of the photocatalyst filter modified by immersing in $\mathrm{LiNO}_{3}$ aqueous solution is finer and smoother such that

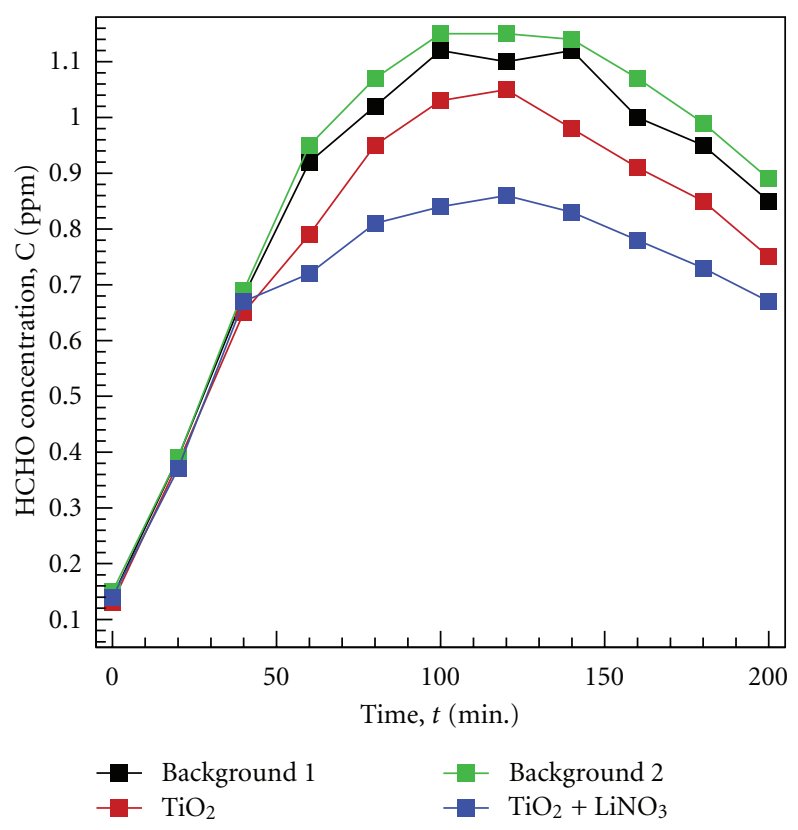

FIGURE 12: The degradation performance for gaseous formaldehyde under irradiation of visible light lamps at $26^{\circ} \mathrm{C}$.

the capacity of adsorbing gaseous formaldehyde is lower. Further, the background concentration at higher ambient temperature is higher because the gaseous molecules more easily vaporize and more dramatically move to lead hardly condensing on the wall of the equipment at higher temperature. From the experimental results, one can find that the higher ambient temperature can enhance the degradation of the photocatalyst filter for the gaseous formaldehyde, and the modified photocatalyst filter has better degradation performance than the original photocatalyst filter for the same test parameters under UVA light irradiation.

3.2.2. Visible Light Irradiation. Figures 12 and 13 illustrate the degradation for gaseous formaldehyde in the cases with different temperature and types of photocatalyst filter under visible light (fluorescent lamps) irradiation. The overall trends of the results in Figures 12 and 13 are substantially consistent with those in Figures 10 and 11, respectively. However, one can find that the degradation of original photocatalyst filter for gaseous formaldehyde is significantly lower than the modified photocatalyst filter under the visible light irradiation. Similarly, the degradation for gaseous formaldehyde is better at the higher ambient temperature under the visible light irradiation. Moreover, the background concentration for the visible light is slightly higher than the UVA light. As the background test is executed in an enclosed space without lights, the background concentration has nothing to do with the illumination wavelength. This phenomenon might be due to the difference in surface adsorption of the lamps. In this study, the performance of degrading gaseous formaldehyde is evaluated as compared with the background test for the same photocatalyst filters 


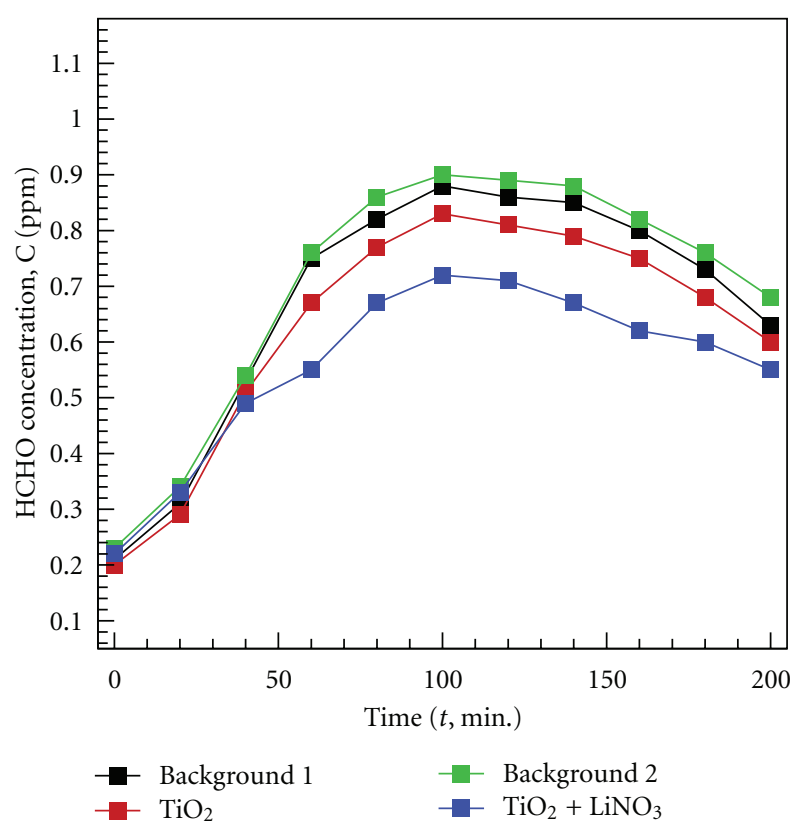

FIGURE 13: The degradation performance for gaseous formaldehyde under irradiation of visible light lamps at $22^{\circ} \mathrm{C}$.

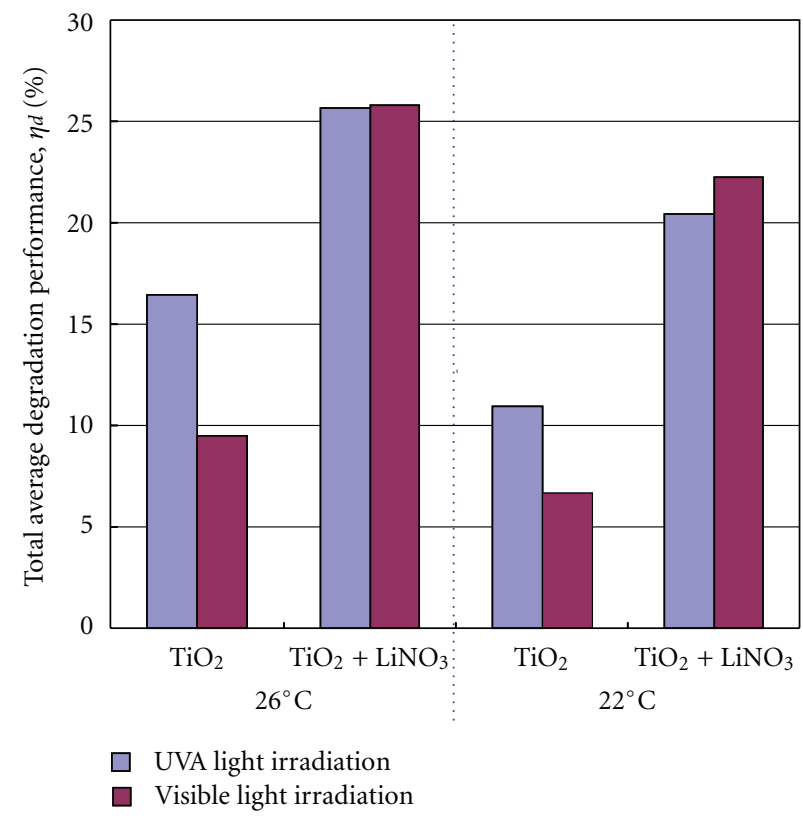

FIGURE 14: The total average degradation performance for gaseous formaldehyde.

and ambient temperature, so the difference in the background value has no effect on evaluating performance.

3.2.3. Comparison of Degradation Performance. All the experiment results in Figures 10 to 13 are summarized in Figure 14. In Figure 14, one can find that the modified photocatalyst filter has much better total average degradation performance for gaseous formaldehyde than the original photocatalyst filter in all the cases. The total average degradation performance of the original photocatalyst filter under visible irradiation is much lower than that under the UVA irradiation. By contrast, the total average degradation performance of the modified photocatalyst filter has little difference between the two light sources. The modified photocatalyst filter has the best performance at $26^{\circ} \mathrm{C}$, and the performance is $9.2 \%$ and $16.3 \%$ higher than that of the original photocatalyst filter for UVA and visible irradiation, respectively. The relevant experimental results confirm that the method proposed in this study to use EPD to fabricate the photocatalyst filter and then modify it by $\mathrm{LiNO}_{3}$ can successfully produce the visible light responsive photocatalyst filter with better performance to effectively degrade gaseous formaldehyde.

\section{Conclusions}

The method to fabricate the photocatalyst filter by EPD and modify it by $\mathrm{LiNO}_{3}$ to be visible light responsive is proposed in this study, which can provide the modified photocatalyst filter with higher degradation performance for gaseous formaldehyde than the original photocatalyst filter in a low-cost and practical way. Through the related tests on the degradation performance for gaseous formaldehyde in all the cases with different ambient temperature, types of filter, and light sources, one can find that the degradation performance of the modified photocatalyst filter for gaseous formaldehyde is much higher than the original photocatalyst filter in all the cases. The best total average degradation performance of the modified photocatalyst filter for gaseous formaldehyde is about $9.2 \%$ and $16.3 \%$ higher than the original photocatalyst filter for UVA and visible irradiation, respectively, at $26^{\circ} \mathrm{C}$. Finally, the related achievements can be also applied to design the photocatalytic air cleaner with visible light responsive function to make the related products be used more efficiently, conveniently, and widely.

\section{Acknowledgment}

This project is funded by National Taiwan Normal University of Taiwan (Contract nos. 98091009 and 98091011).

\section{References}

[1] Y. Zhang, R. Yang, and R. Zhao, "A model for analyzing the performance of photocatalytic air cleaner in removing volatile organic compounds," Atmospheric Environment, vol. 37, no. 24, pp. 3395-3399, 2003.

[2] C. H. Ao and S. C. Lee, "Indoor air purification by photocatalyst $\mathrm{TiO}_{2}$ immobilized on an activated carbon filter installed in an air cleaner," Chemical Engineering Science, vol. 60, no. 1, pp. 103-109, 2005.

[3] J. P. Mo, Y. P. Zhang, Q. Xu, J. J. Lamson, and R. Zhao, "Photocatalytic purification of volatile organic compounds in indoor air: a literature review," Atmospheric Environment, vol. 43, no. 14, pp. 2229-2246, 2009.

[4] C. H. Ao and S. C. Lee, "Enhancement effect of $\mathrm{TiO}_{2} \mathrm{immo-}^{-}$ bilized on activated carbon filter for the photodegradation of 
pollutants at typical indoor air level," Applied Catalysis B, vol. 44, no. 3, pp. 191-205, 2003.

[5] J. M. Peralta-Hernández, J. Manríquez, Y. Meas-Vong et al., "Photocatalytic properties of nano-structured $\mathrm{TiO}_{2}$ films obtained by means of electrophoretic deposition," Journal of Hazardous Materials, vol. 147, no. 1-2, pp. 588-593, 2007.

[6] C. C. Chen, W. J. Yang, and C. Y. Hsu, "Investigation into the effects of deposition parameters on $\mathrm{TiO}_{2}$ photocatalyst thin films by rf magnetron sputtering," Superlattices and Microstructures, vol. 46, no. 3, pp. 461-468, 2009.

[7] P. Evans and D. W. Sheel, "Photoactive and antibacterial $\mathrm{TiO}_{2}$ thin films on stainless steel," Surface and Coatings Technology, vol. 201, no. 22-23, pp. 9319-9324, 2007.

[8] S. H. Zhang, B. F. Hu, B. Xie, S. Y. Zhang, and F. Y. Li, "Preparation of titania film by pyrolysis of chelated tetrabutyl titanate," Key Engineering Materials, vol. 368-372, pp. 14681470, 2008.

[9] J. Yu and X. Zhao, "Effect of substrates on the photocatalytic activity of nanometer $\mathrm{TiO}_{2}$ thin films," Materials Research Bulletin, vol. 35, no. 8, pp. 1293-1301, 2000.

[10] J. Van Tassel and C. A. Randall, "Electrophoretic deposition and sintering of thin/thick PZT films," Journal of the European Ceramic Society, vol. 19, no. 6-7, pp. 955-958, 1999.

[11] C. Kaya, F. Kaya, A. R. Boccaccini, and K. K. Chawla, "Fabrication and characterisation of Ni-coated carbon fibre-reinforced alumina ceramic matrix composites using electrophoretic deposition," Acta Materialia, vol. 49, no. 7, pp. 1189-1197, 2001.

[12] C. Du, D. Heldbrant, and N. Pan, "Preparation and preliminary property study of carbon nanotubes films by electrophoretic deposition," Materials Letters, vol. 57, no. 2, pp. 434-438, 2002.

[13] O. van der Biest, S. Put, G. Anné, and J. Vleugels, "Electrophoretic deposition for coatings and free standing objects," Journal of Materials Science, vol. 39, no. 3, pp. 779-785, 2004.

[14] L. Besra and M. Liu, "A review on fundamentals and applications of electrophoretic deposition (EPD)," Progress in Materials Science, vol. 52, no. 1, pp. 1-61, 2007.

[15] S. Yanagida, A. Nakajima, Y. Kameshima, N. Yoshida, T. Watanabe, and K. Okada, "Preparation of a crack-free rough titania coating on stainless steel mesh by electrophoretic deposition," Materials Research Bulletin, vol. 40, no. 8, pp. 13351344, 2005.

[16] M. J. Santillán, F. Membrives, N. Quaranta, and A. R. Boccaccini, "Characterization of $\mathrm{TiO}_{2}$ nanoparticle suspensions for electrophoretic deposition," Journal of Nanoparticle Research, vol. 10, no. 5, pp. 787-793, 2008.

[17] S. Dor, S. Ruhle, A. Ofir, M. Adler, L. Grinis, and A. Zaban, "The influence of suspension composition and deposition mode on the electrophoretic deposition of $\mathrm{TiO}_{2}$ nanoparticle agglomerates," Colloids and Surfaces A, vol. 342, no. 1-3, pp. 70-75, 2009.

[18] S. Bonnas, H. J. Ritzhaupt-Kleissl, and J. Haußelt, "Electrophoretic deposition for fabrication of ceramic microparts," Journal of the European Ceramic Society, vol. 30, no. 5, pp. 1159-1162, 2010.

[19] B. Ferrari, J. C. Fariñas, and R. Moreno, "Determination and control of metallic impurities in alumina deposits obtained by aqueous electrophoretic deposition," Journal of the American Ceramic Society, vol. 84, no. 4, pp. 733-739, 2001.

[20] F. Q. Tang, T. Uchikoshi, K. Ozawa, and Y. Sakka, "Effect of polyethylenimine on the dispersion and electrophoretic deposition of nano-sized titania aqueous suspensions," Journal of the European Ceramic Society, vol. 26, no. 9, pp. 1555-1560, 2006.

[21] S. Lebrette, C. Pagnoux, and P. Abelard, "Fabrication of titania dense layers by electrophoretic deposition in aqueous media," Journal of the European Ceramic Society, vol. 26, no. 13, pp. 2727-2734, 2006.

[22] L. Besra, T. Uchikoshi, T. S. Suzuki, and Y. Sakka, "Application of constant current pulse to suppress bubble incorporation and control deposit morphology during aqueous electrophoretic deposition (EPD)," Journal of the European Ceramic Society, vol. 29, no. 10, pp. 1837-1845, 2009.

[23] B. Raissi, E. Marzbanrad, and A. R. Gardeshzadeh, "Particle size separation by alternating electrophoretic deposition," Journal of the European Ceramic Society, vol. 29, no. 15, pp. 3289-3291, 2009.

[24] F. Q. Tang, Y. Sakka, and T. Uchikoshi, "Electrophoretic deposition of aqueous nano-sized zinc oxide suspensions on a zinc electrode," Materials Research Bulletin, vol. 38, no. 2, pp. 207-212, 2003.

[25] D. Zhitomirsky, J. A. Roether, A. R. Boccaccini, and I. Zhitomirsky, "Electrophoretic deposition of bioactive glass/polymer composite coatings with and without HA nanoparticle inclusions for biomedical applications," Journal of Materials Processing Technology, vol. 209, no. 4, pp. 1853-1860, 2009.

[26] W. Yin, W. Wang, L. Zhou, S. Sun, and L. Zhang, "CTABassisted synthesis of monoclinic $\mathrm{BiVO}_{4}$ photocatalyst and its highly efficient degradation of organic dye under visible-light irradiation," Journal of Hazardous Materials, vol. 173, no. 1-3, pp. 194-199, 2010.

[27] V. Brezová, A. Blažková, Ľ. Karpinský et al., "Phenol decomposition using $\mathrm{M}^{n+} / \mathrm{TiO}_{2}$ photocatalysts supported by the solgel technique on glass fibres," Journal of Photochemistry and Photobiology A, vol. 109, no. 2, pp. 177-183, 1997.

[28] T. López, J. Hernandez-Ventura, R. Gómez et al., "Photodecomposition of 2, 4-dinitroaniline on $\mathrm{Li} / \mathrm{TiO}_{2}$ and $\mathrm{Rb} / \mathrm{TiO}_{2}$ nanocrystallite sol-gel derived catalysts," Journal of Molecular Catalysis A, vol. 167, no. 1-2, pp. 101-107, 2001.

[29] Y. Bessekhouad, D. Robert, J. V. Weber, and N. Chaoui, "Effect of alkaline-doped $\mathrm{TiO}_{2}$ on photocatalytic efficiency," Journal of Photochemistry and Photobiology A, vol. 167, no. 1, pp. 49-57, 2004.

[30] R. C.W. Lam, M. K. H. Leung, D. Y. C. Leung, L. L. P. Vrijmoed, W. C. Yam, and S. P. Ng, "Visible-light-assisted photocatalytic degradation of gaseous formaldehyde by parallel-plate reactor coated with $\mathrm{Cr}$ ion-implanted $\mathrm{TiO}_{2}$ thin film," Solar Energy Materials and Solar Cells, vol. 91, no. 1, pp. 54-61, 2007.

[31] S. Yin, P. Zhnag, B. Liu et al., "Microwave-assisted hydrothermal synthesis of monoclinic nitrogen-doped titania photocatalyst and its DeNOx ability under visible LED light irradiation," Research on Chemical Intermediates, vol. 36, no. 1, pp. 69-75, 2010.

[32] J. Yu, M. Zhou, B. Cheng, and X. Zhao, "Preparation, characterization and photocatalytic activity of in situ N,Scodoped $\mathrm{TiO}_{2}$ powders," Journal of Molecular Catalysis A, vol. 246, no. 1-2, pp. 176-184, 2006.

[33] M. Zhou and J. Yu, "Preparation and enhanced daylightinduced photocatalytic activity of C,N,S-tridoped titanium dioxide powders," Journal of Hazardous Materials, vol. 152, no. 3, pp. 1229-1236, 2008.

[34] J. A. Byrne, P. A. Fernandez-Ibañez, P. S. M. Dunlop, D. M. A. Alrousan, and J. W. J. Hamilton, "Photocatalytic enhancement for solar disinfection of water: a review," International Journal of Photoenergy, vol. 2011, Article ID 798051, 12 pages, 2011. 
[35] T. Ochiai, K. Nakata, T. Murakami et al., "Development of solar-driven electrochemical and photocatalytic water treatment system using a boron-doped diamond electrode and $\mathrm{TiO}_{2}$ photocatalyst," Water Research, vol. 44, no. 3, pp. 904 910, 2010

[36] G. Dai, J. Yu, and G. Liu, "Synthesis and enhanced visiblelight photoelectrocatalytic activity of p-n junction $\mathrm{BiOI} / \mathrm{TiO}_{2}$ nanotube arrays," The Journal of Physical Chemistry C, vol. 115, pp. 7339-7346, 2011.

[37] B. Huang and S. Saka, "Photocatalytic activity of $\mathrm{TiO}_{2}$ crystallite-activated carbon composites prepared in supercritical isopropanol for the decomposition of formaldehyde," Journal of Wood Science, vol. 49, no. 1, pp. 79-85, 2003.

[38] H. Ichiura, T. Kitaoka, and H. Tanaka, "Removal of indoor pollutants under UV irradiation by a composite $\mathrm{TiO}_{2}$-zeolite sheet prepared using a papermaking technique," Chemosphere, vol. 50, no. 1, pp. 79-83, 2003.

[39] T. Liu, F. Li, and X. $\mathrm{Li}$, " $\mathrm{TiO}_{2}$ hydrosols with high activity for photocatalytic degradation of formaldehyde in a gaseous phase," Journal of Hazardous Materials, vol. 152, no. 1, pp. 347-355, 2008.

[40] L. Wang, M. Sakurai, and H. Kameyama, "Study of catalytic decomposition of formaldehyde on $\mathrm{Pt} / \mathrm{TiO}_{2}$ alumite catalyst at ambient temperature," Journal of Hazardous Materials, vol. 167, no. 1-3, pp. 399-405, 2009.

[41] Y. Li, Y. Jiang, S. Peng, and F. Jiang, "Nitrogen-doped $\mathrm{TiO}_{2}$ modified with NH4F for efficient photocatalytic degradation of formaldehyde under blue light-emitting diodes," Journal of Hazardous Materials, vol. 182, no. 1-3, pp. 90-96, 2010.

[42] JCPDS-ICDD, "The International Centre for Diffraction Data," PCPDFWIN 2.4, 2003.

[43] ASHRAE, ASHRAE Handbook-HVAC Systems and Equipment (SI), American Society of Heating, Refrigerating and AirConditioning Engineers, Atlanta, Ga, USA, 2008. 


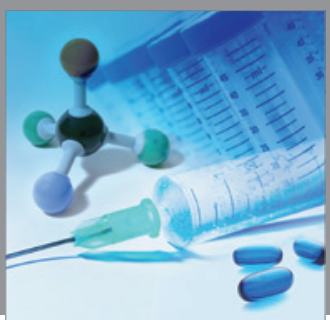

International Journal of

Medicinal Chemistry

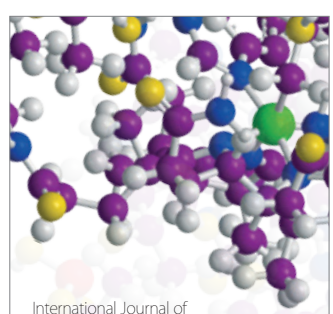

Carbohydrate Chemistry

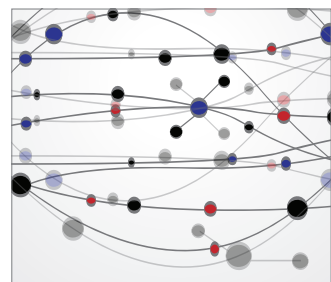

The Scientific World Journal
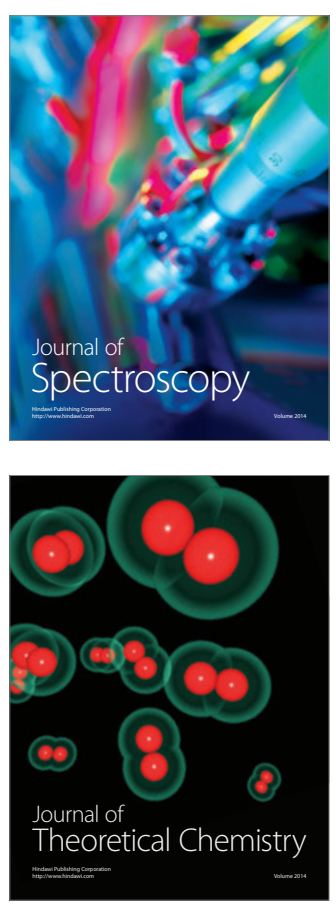
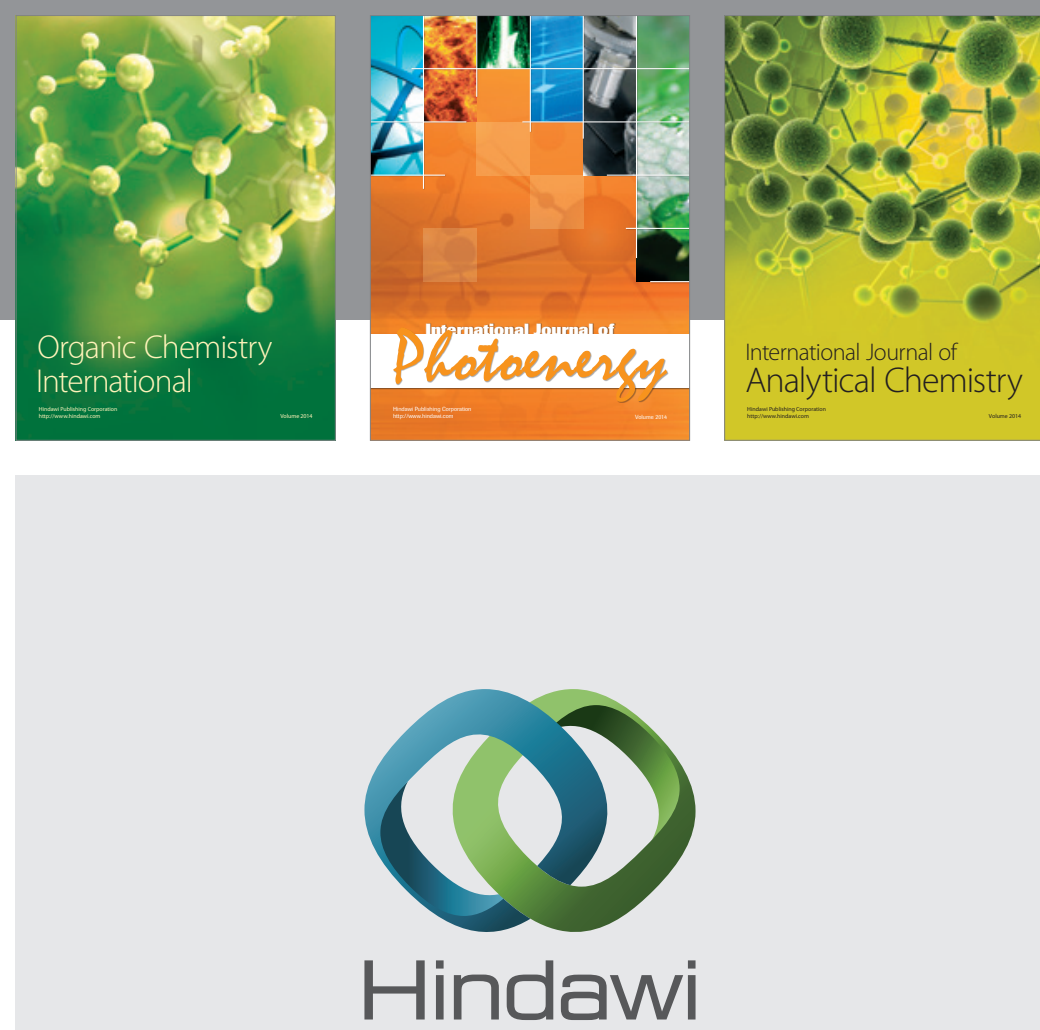

Submit your manuscripts at

http://www.hindawi.com
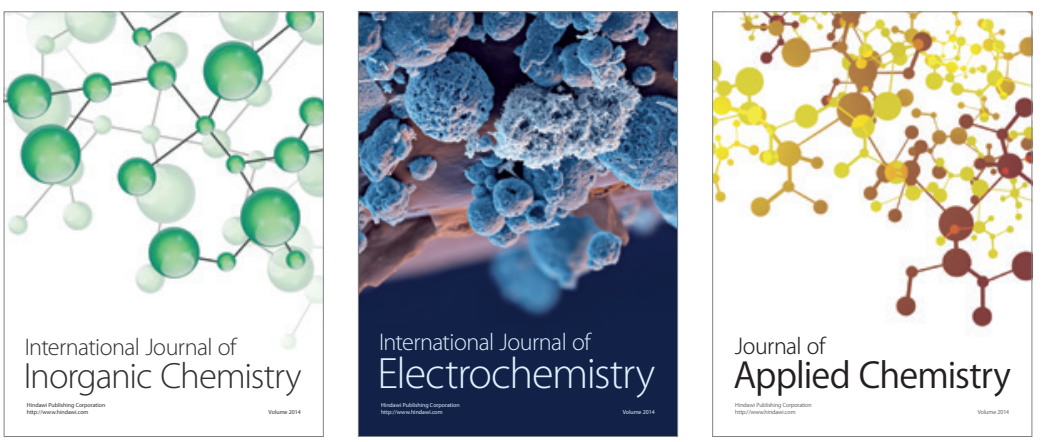

Journal of

Applied Chemistry
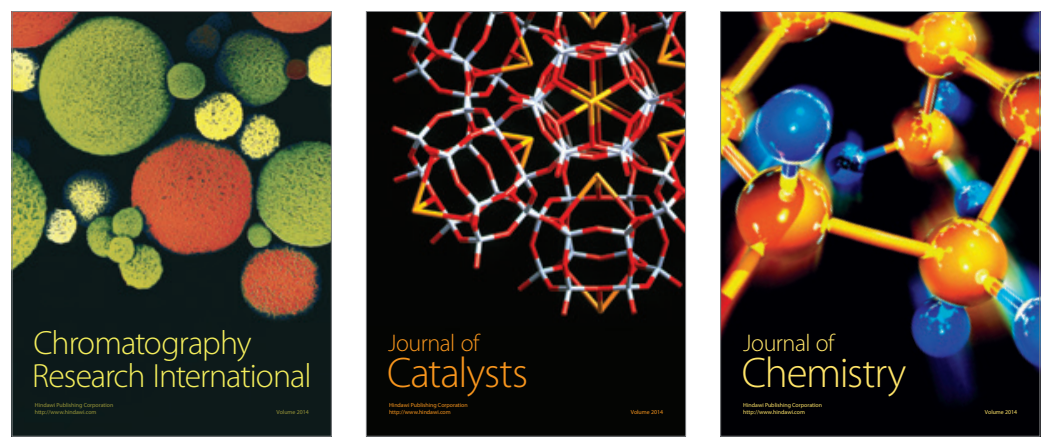
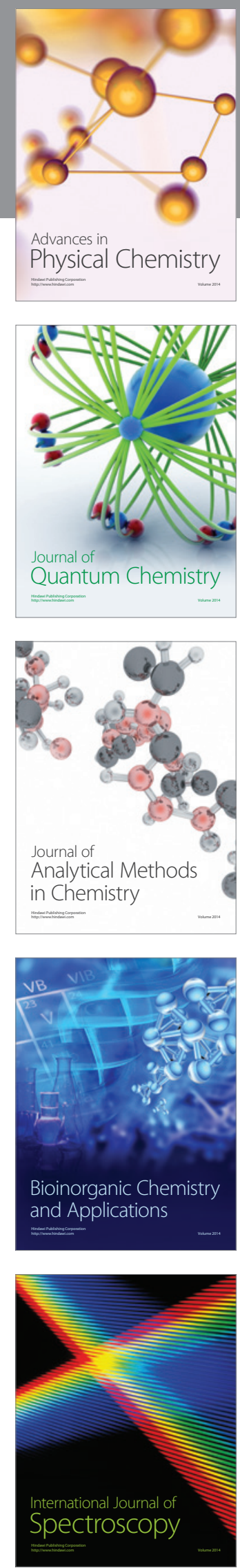